\title{
Optimum design and dynamic simulation of the friction pairs between the eccentric crankshaft and the connecting rod in crankshaft piston motors
}

\author{
CHEN ZHUORU • , LIANG XINGUI, ZHANG SHOULI, and JIN CHAOMING \\ Dept. of Power Engineering, Harbin Institute of Technology, Harbin 150006, P. R. China
}

\begin{abstract}
In this paper, an equation for the structural parameters of the hydrostatic bearing in a friction pair between eccentric crankshaft and connecting rod slipper-pad has been derived by means of an equivalent electrical net. A mathematical model for optimization of the slipper-pad has been established. With the aid of a computer, the optimal structural parameters have been obtained. Meanwhile, on the model for the dynamic characteristics of the bearing established, dynamic simulation has been performed. The extrusion effect of oil film on dynamic response has been discussed. Finally, the above analysis have proved that the optimum design is reasonable and reliable, and some favorable conclusions have been drawn.
\end{abstract}

\section{KEYWORDS}

Hydrostatic bearing, Friction pair, Optimization, Dynamic simulation, Extrusion effect

\section{NOMENCLATURE}

$A=$ slipper-pad area

$A_{p}=$ piston area

$A_{s}=$ equivalent bearing area

$B, b_{B}, b_{1}, B_{1}=$ bearing dimensions

$\mathrm{d}_{\mathrm{p}}=$ diameter of the piston

$\mathrm{d}_{\mathrm{c}}=$ diameter of the capillary tube

$\mathrm{e}=$ eccentricity

$\mathrm{h}=$ clearance

$h_{0}=$ static film thickness

I=length of the connecting rod

$\mathrm{L}, \mathrm{L}_{1}=$ bearing dimensions

$l_{c}=$ length of the capillary tube
$\mathrm{M}=$ mass of the piston and connecting rod

$\mathrm{n}=$ rotation speed of the eccentric crankshaft

$\mathrm{p}=$ supply pressure

$\mathrm{P}_{\mathrm{S}}=$ pocket pressure

$\mathrm{R}=$ radius of eccentric

$\mathrm{R}_{1}=$ fixed restrictor

$\mathrm{R}_{2}=$ variable restrictor

$\mathrm{t}=$ time

$\Delta t=$ response time of pocket pressure

$\mathrm{V}=$ approaching velocity of slipper-pad

$\mathrm{W}=$ load of cylinder

$\mathrm{W}_{\mathrm{i}}=$ load-carrying capacity of bearing

$\mathrm{Y}=$ displacement of slipper-pad

- Chen Zhuoru is the professor and dean of the power engeneering dept. HIT. 
$z=$ number of cylinders

$\alpha=$ bearing function

$\theta_{\mathrm{i}}=$ angle of inclination of connecting rod

$\mu=$ absolute viscosity of fluid

\section{INTRODUCTION}

The friction pair between eccentric crankshaft and connecting rod in a crankshaft piston motor is the key motion pair transmitting forces. It is because its power loss is smaller, its life time is longer and its transmission efficiency, especially the efficiency of starting torque, is higher. Therefore the hydrostatic bearing is very suitable for the working conditions of crankshaft piston motors.

For the hydrostatic bearing in a pair there are many structural parameters. It is very difficult, by the conventional methods, to deal with the mutually restricted relations among the structural parameters and their effects on transmission efficiency, let alone to obtain the optimal parameters. These problems can be resolved by the optimization method presented in this paper. In addition, the dynamic characteristics of the bearing are analyzed and discussed, and some reasonable conclusions are given.

\section{THEORETICAL ANALYSIS OF HYDRO- STATIC BEARING}

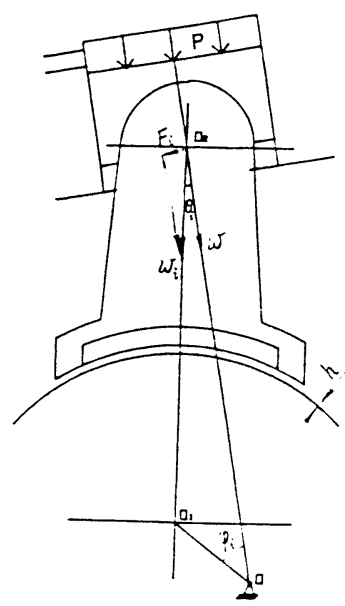

Fig 1. Digramatic cross-sectional view of the cylinder
1. Load of the Hydrostatic Bearing

In Figure 1, $\mathrm{W}=\mathrm{PA}_{\mathrm{p}}$

$$
\mathrm{W}_{\mathrm{i}}=\mathrm{W} / \cos \theta_{\mathrm{i}}
$$

where, $A_{p}=\frac{\pi}{4} d_{p}^{2}$

For $\theta_{\mathrm{i}} \leqslant 12^{\circ}$, the load capacity of the hydrostatic bearing $\mathrm{W}_{\mathrm{i}}$ can be varied within $\mathrm{W}_{\mathrm{i}} \sim 1$. $02 \mathrm{~W}$. Theoretically, we assume that $\mathrm{W}_{\mathrm{i}}=\mathrm{W}$ approximately.

2. Model of the Hydrostatic Bearing

In most applications, oil film thickness is very small and the flow in the sealing lands of the bearing is a laminar flow. It is reasonable to assume that the pressure distribution in the lands is linear, i. e, we assume that the bearing surfaces are paralle and the temperature rise in the fluid is negligible as it flows in the land. According to the mean length and mean width method, the bearing load capacity (Figure 2) is: [5] [6]

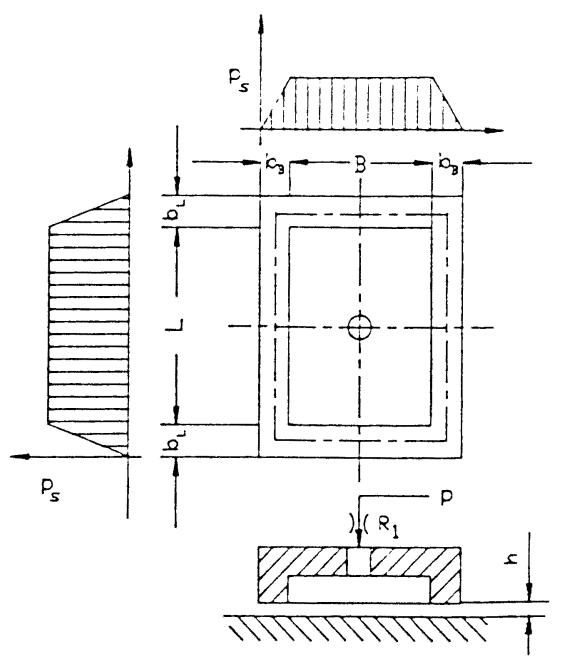

Fig 2. Hydrostatic bearing of slipper-pad

$$
\mathrm{W}_{\mathrm{s}}=\mathrm{P}_{\mathrm{s}} \mathrm{A}_{\mathrm{s}}
$$

where, $A_{s}=\left(B+b_{B}\right)\left(L+b_{L}\right)$

The flowing field of the hydrostatic bearing can be simplified into an equivalent electrical net (Figure 3). The fluid resistance through each sealing land is as follows:

$\mathrm{R}_{11}=\mathrm{R}_{11}{ }^{\prime}=\frac{12 \mu \mathrm{b}_{\mathrm{L}}}{\left(\mathrm{B}+\mathrm{b}_{\mathrm{B}}\right) \mathrm{h}^{3}}$

$\mathrm{R}_{22}=\mathrm{R}_{22}^{\prime}=\frac{12 \mu \mathrm{b}_{\mathrm{B}}}{\left(\mathrm{L}+\mathrm{b}_{\mathrm{L}}\right) \mathrm{h}^{3}}$

$\mathrm{R}_{11}, \mathrm{R}_{11}{ }^{\prime}, \mathrm{R}_{22}, \mathrm{R}_{22}{ }^{\prime}$ are parallel connections, and so the total fluid resistance of the flow 


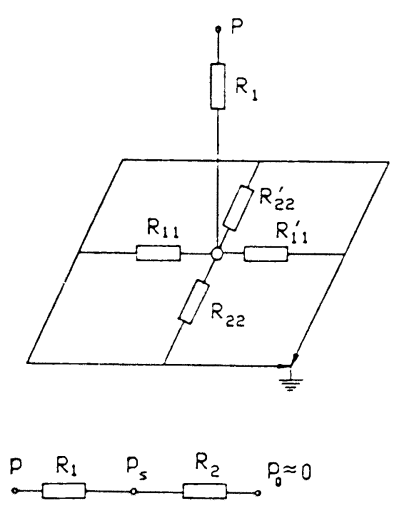

Fig 3. Equivalent electrical net through all lands is

$$
\begin{aligned}
\mathrm{R}_{2}= & \left(\frac{1}{\mathrm{R}_{11}}+\frac{1}{\mathrm{R}_{11}}+\frac{1}{\mathrm{R}_{22}}+\frac{1}{\mathrm{R}_{22}{ }^{\prime}}\right)^{-1} \\
& =\frac{6 \mu}{h^{3}\left(\frac{\mathrm{B}+\mathrm{b}_{\mathrm{B}}}{\mathrm{b}_{\mathrm{L}}}+\frac{\mathrm{L}+\mathrm{b}_{\mathrm{L}}}{\mathrm{L}}\right)}
\end{aligned}
$$

The flow through the lands is

$$
\mathrm{q}_{2}=\mathrm{P}_{\mathrm{S}} / \mathrm{R}_{2}
$$

and the flow through a capillary tube is

$$
\mathrm{q}_{1}=\left(\mathrm{p}-\mathrm{p}_{\mathrm{s}}\right) / \mathrm{R}_{1}
$$

where

$$
\mathrm{R}_{1}=\frac{128 \mu \mathrm{l}_{\mathrm{c}}}{\pi \mathrm{d}_{\mathrm{c}}^{4}}
$$

From Eqs. (5), (6), (7) and (8), the bearing equation can be solved as follows:

$$
\alpha=\mathrm{P}_{\mathrm{S}} / \mathrm{P}_{1}=\frac{1}{1+\mathrm{Kh}^{3}}
$$

where, $\mathrm{K}=\mathrm{R}_{1} / \mathrm{K}_{\mathrm{B}}$

$$
\mathrm{K}_{\mathrm{B}}=\frac{6 \mu}{\left(\mathrm{B}+\mathrm{b}_{\mathrm{B}}\right) / \mathrm{b}_{\mathrm{L}}+\left(\mathrm{L}+\mathrm{b}_{\mathrm{L}}\right) / \mathrm{b}_{\mathrm{B}}}
$$

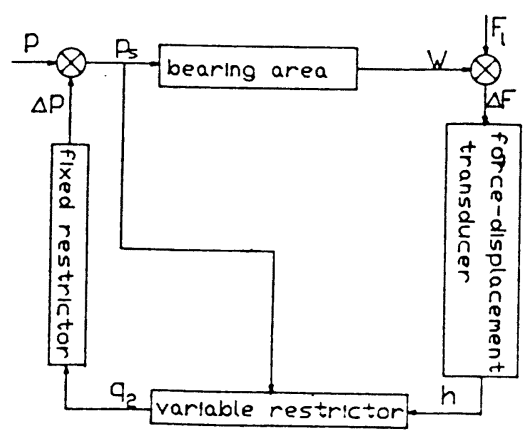

Fig 4. Block diagram of hydrostatic bearing
In Figure 4, the bearing is an automatically controlled system with a pressure feed, and the bearing clearance is of a three functions:

(1) It can carry an external load;

(2) It can act as a force-displacement transducer;

(3) It can be used as a variable restrictor.

\section{OPTIMIZATION MODEL}

1. Optimization Variable $X$ $x=[X(1), X(2), X(3), X(4), X(5), X$ (6), $\mathrm{X}(7)]$

$=\left[\mathrm{B}, \mathrm{L}, \mathrm{b}_{\mathrm{B}}, \mathrm{b}_{\mathrm{L}}, \mathrm{l}_{\mathrm{c}}, \mathrm{d}_{\mathrm{c}}, 1000 \mathrm{~h}\right]$

2. Objective function $F(X)$

The total power loss, including power lost in friction and leakage, is chosen as the sole minimum objective function, i. e

$\mathrm{F}_{\mathrm{f}} \approx \mu \mathrm{Ac}(\mathrm{v})^{2} / \mathrm{h}$

$\mathrm{F}_{\mathrm{V}}=\mathrm{K}_{\mathrm{q}} \mathrm{p}_{s}^{2} \mathrm{~h}^{\mathrm{S}}$

$\mathrm{F}(\mathrm{x})=\mathrm{F}_{\mathrm{f}}+\mathrm{F}_{\mathrm{V}}$

where, $A_{c}=\left(B+2 b_{B}\right)\left(L+2 b_{L}\right)$

$$
\mathrm{K}_{\mathrm{q}}=\frac{1}{\mathrm{~K}_{\mathrm{B}}}
$$

3. Constraint Conditions $G(X)$

a. Balance of Force

In the above discussion, we assume that $\mathrm{W}$ $=\mathrm{W}_{\mathrm{i}}$, According to Eq. (9), there is a constraint condition of equality as follows :

$$
G_{1}(X)=A_{p} / A_{s}-\left(1+K_{h}^{3}\right)^{-1}=0
$$

b. Size Parameters of Slipper-pad[6]

$$
0.1<b_{B} / B=b_{L} / L<0.2
$$

Thus,

$$
\left.\begin{array}{l}
G_{2}(X)=0.1-X(3) / X(1) \leqslant 0 \\
G_{3}(X)=0.1-X(4) / X(2) \leqslant 0 \\
G_{4}(X)=X(3) / X(1)-0.2 \leqslant 0 \\
G_{5}(X)=X(4) / X(1)-0.2 \leqslant 0
\end{array}\right\}
$$

c. Bearing Function

With the oil film rigidity and the structural parameters of slipper-pad, the bearing function should be within $(0.8 \sim 0.9)$, i. e, [5] [6]

$\left.\mathrm{G}_{6}(\mathrm{X})=0.8-2 \leqslant 0\right\}$

$\left.\mathrm{G}_{7}(\mathrm{X})=2-0.9 \leqslant 0\right\}$

d. Ratio of Areas

A slipper-pad bearing with good fitting for surfaces, the minimum ratio of the pocket area to the cylinder area should ensure bear- 
ing $0.42[3]$ :

$$
\mathrm{G}_{8}(\mathrm{X})=0.42-\mathrm{BL} / \mathrm{A}_{\mathrm{p}} \leqslant 0
$$

For a five-cylinder motor, the minimum eccentric wheel radius of which the slipper pads don't collide with each other is writen by :

$$
\left.\begin{array}{l}
\mathrm{R}_{\min }=1.024\left[\mathrm{~B}+2 \mathrm{~b}_{\mathrm{B}}+1 \sim 4 \mathrm{~mm}\right] \\
\mathrm{G}_{9(\mathrm{X})}=R-1.024\left[\mathrm{~B}+2 \mathrm{~b}_{\mathrm{B}}+4\right]<0 \\
\mathrm{G}_{10(\mathrm{X})}=1.024\left[\mathrm{~B}+2 \mathrm{~b}_{\mathrm{B}}+1\right]-\mathrm{R}<0
\end{array}\right\}
$$

At the starting moment for motor operating, the bearing pressure in the pocket area has not been presented yet. The contacting pressure $p_{c}$ between metals should be no more than their minimum allowance pressure $\left[\mathrm{p}_{c}\right]$, i. e, [5]

$$
\begin{aligned}
G_{11(X)} & =p_{c}-\left[p_{c}\right]<0 \\
\text { where, } p_{c} & =\frac{W_{i}}{A-X(1) X(3)}
\end{aligned}
$$

\section{EXAMPLE FOR OPTIMIZATION APPLI- CATION}

For a five-cylinder radial-piston motor, $\mathrm{p}=$ $20 \mathrm{MPa}, \mathrm{n}=320 \mathrm{r} / \mathrm{min}, \mathrm{v}=1 \mathrm{l} / \mathrm{r}, \mathrm{R}=65 \mathrm{~mm}$, $\mathrm{l}=75 \mathrm{~mm}, \mathrm{e}=30 \mathrm{~mm}$. Absolute viscosity of hydraulic oil $=2.6754 \times 10^{-2} \mathrm{~Pa}$. S at $50 \mathrm{C}$. By the method of Constraint Variable Metric Optimization program CVMO1, the results are as follows:

$$
X=[48.81,59.44,6.83,8.32,15 ., 0.6,
$$
$21.863] \mathrm{mm}$

From Table 1, it can be known that compared with the conventional methods the volume efficiency and mechanical efficiency of the bearing by optimization are higher, this may be a good foundation to improve the total efficiency of machines. The value of volume efficiency shows that power lost in leakage is usually below $1.3 \%[3]$.

\section{THEORETICAL ANALYSIS OF DYNAMIC CHARACTERISTICS OF BEARING}

When a piston changes from an exhaust stroke to a working stroke (Fig. 5) within the time $t$, the piston will press the connecting rod, then pressure will be established in bearing pocket after time $\Delta t$.

Within the time $\Delta t$, the motion equation of slipper is written as:

$$
M \frac{d^{2} y}{d t^{2}}+N\left(h_{0}-y\right) \frac{d y}{d t}=p A_{p}
$$

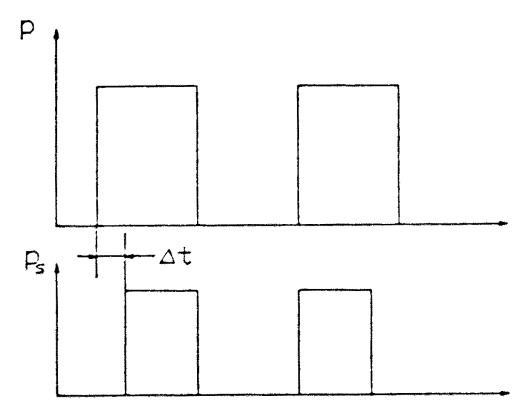

Fig 5. Step changes of supply pressure where, $M=2.5 \mathrm{~kg}$.

$$
\begin{aligned}
N\left(h_{0}-y\right) & =\frac{2 \mu}{\left(h_{0}-y\right)^{3}}\left[\left(B+b_{B}\right) b_{L}^{3}\right. \\
& \left.+\left(L+b_{L}\right) b_{B}\right]
\end{aligned}
$$

Initials, $\left.\mathrm{Y}\right|_{\mathrm{t}=0}=0, \mathrm{~V}=\mathrm{dy} /\left.\mathrm{dt}\right|_{\mathrm{t}=0}=0$

Its simulation graph is shown in Figure 6.

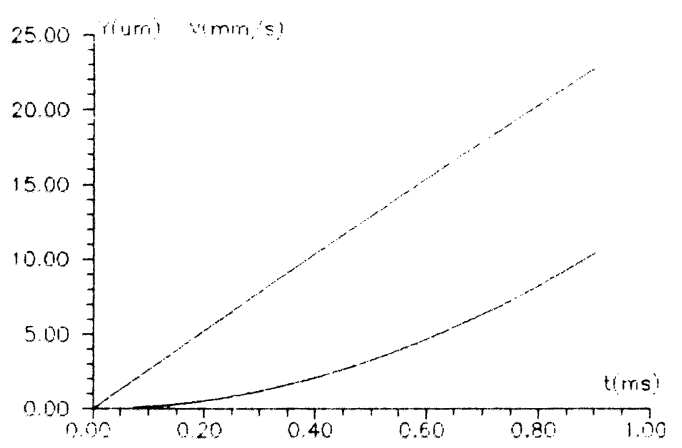

Fig 6. When $t \leqslant \Delta t$, dynamic variations

Motion Equation of Bearing Slipper-pad When $t>\Delta t$, the pressure in the pocket is presented. Its equilibrium to the force from the piston revents the film from becoming smaller and recovers the bearing work near the static film as soon as possible.

For the sake of the velocity $\mathrm{V}$ of slipper-pad approaching to the eccentric surface, the leakage through the bearing lands is

$$
\mathrm{q}_{2}^{\prime}=\mathrm{p}_{\mathrm{s}} / \mathrm{R}_{2}+\mathrm{VA} \mathrm{A}_{\mathrm{S}}-\mathrm{VA}
$$

where, $A=\left(B+2 b_{B}\right)\left(L+2 b_{L}\right)$

For the continuity of flow, there is

$$
\mathrm{q}_{1}^{\prime}=\mathrm{q}_{2}^{\prime}+\mathrm{VA}
$$

The motion equation of the slipper-pad is 
$M \frac{d^{2} y}{d t^{2}}+N\left(h_{0}-y\right) \frac{d y}{d t}+2 R_{1} A \xi \frac{d y}{d t}=p A_{P}-$ $p_{S} A_{S}$

the initial conditions: $\left.\mathrm{y}\right|_{\mathrm{t}=0}=\left.\mathrm{y}\right|_{\Delta \mathrm{t}},\left.\mathrm{V}\right|_{\mathrm{t}=0}=$ $\mathrm{dy} /\left.\mathrm{dt}\right|_{\Delta \mathrm{t}}$

Figure 7 shows the theoretical response of the displacement $\mathrm{Y}$ and the velocity $\mathrm{V}$ of the slipper-pad to a stop change in supplying a pressure of $20 \mathrm{MPa}$. The minimum film thickness is beyond $10 \mu \mathrm{m}$, and so it can satisfy the demand for the bearing operating.

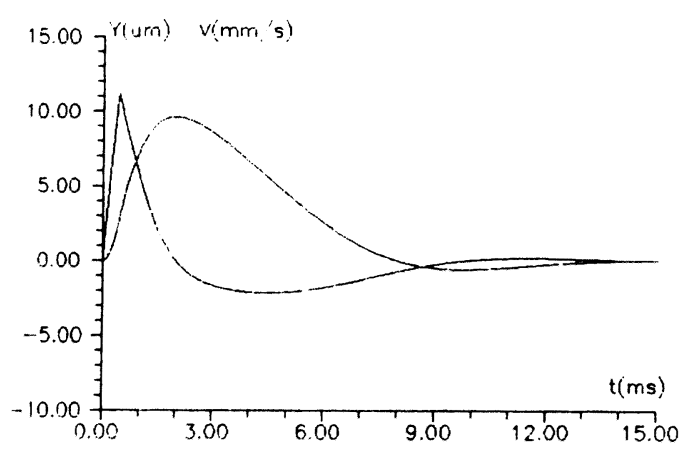

Fig 7. Dynamic variations of slipper-pad Dynamic Response of Oil Film

We can know the bearing film thickness $\left(h_{0}\right.$ $-y)$ from the displacement y of bearing slipper-pad. The response of bearing oil film to a step change in supplying a pressure of $20 \mathrm{MPa}$ is shown in Figure 8.

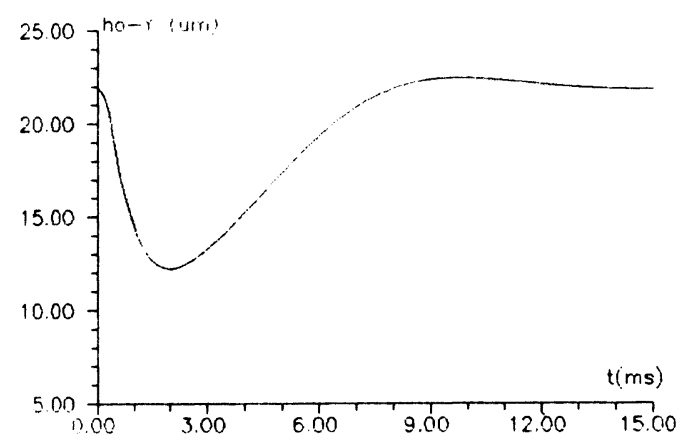

Fig 8. Dynamic Variations of hydrostatics bearing of oil film

If no extrusion effect of oil is taken into consideration, we assume that the formula containing $\mathrm{dy} / \mathrm{dt}$ in Eq. (24) should be negligible also, and now, the equation of the bearing is

$$
\mathrm{M} \frac{\mathrm{d}^{2} \mathrm{y}}{\mathrm{dt}^{2}}=\mathrm{pA}_{\mathrm{p}}-\mathrm{ps}_{\mathrm{s}} \mathrm{A}_{\mathrm{s}}
$$

The dynamic simulation of the bearing is shown in Figure 9. The response process of oil film is divergent and vibration in equal amplitude occurs same range.

Figure 10 shows a hydrostatic slipper-pad with auxiliary bearing flats. Their purpose is :

(1). to increase the extrusion effect and decrease the dynamic change range of bearing film.

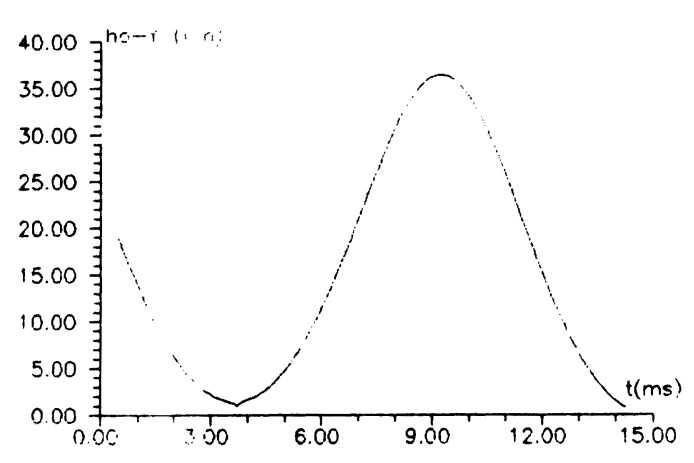

Fig 9. Dynamic variations of oil film without squeeze

(2) to weaken the contact pressure at the moment when a motor is starting.

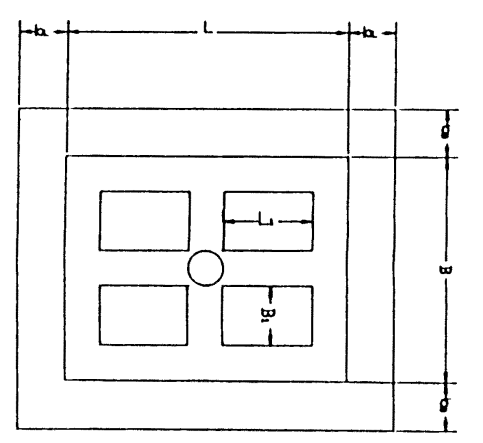

Fig 10. Notation of slipper-pad dimensions with assistant bearing flats

When $\mathrm{dh} / \mathrm{dx}=0$, and $\mathrm{dh} / \mathrm{dt}=\mathrm{V}$, the load capacity of the bearing is as follows:

$$
\begin{gathered}
\mathrm{W}_{1}=2 \int_{0}^{L_{1} / 2} \int_{0}^{B_{1}} p_{1} d x d y \\
=\frac{192 \mu B_{1}^{3} \mathrm{~V}}{\pi^{3} h^{3}} \sum_{n=1,3,5}^{\infty}\left(\frac{B_{1}}{n^{5} \pi} \tanh \frac{n \pi L_{1}}{2 B_{1}}-\frac{L_{1}}{2 n^{4}}\right)
\end{gathered}
$$

Its solutions are the dynamic reponse of the film thickness in Figure 11. 


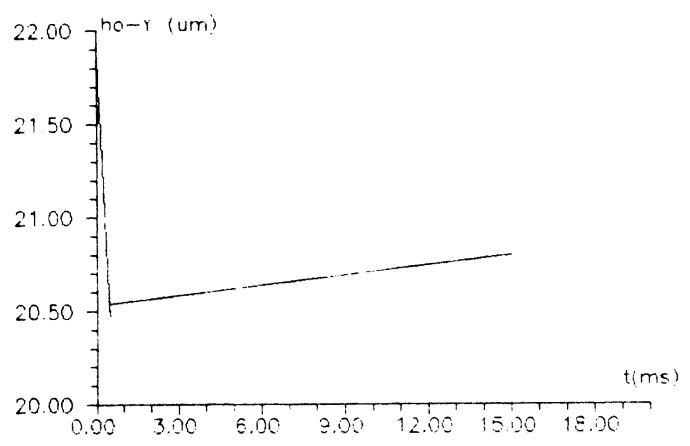

Fig 11. Dynamic variations of oil film with auxiliary bearing flats

\section{CONCLUSIONS}

The method of optimization applied to the pairs between eccentric crankshaft and connecting rod slipper-pad in a piston motor has many advatages over the conventional methods. It is very favorable to improve the synthetic performance of motors. Meanwhile, under the premise to ensure the single or multiple optimum objective functions, designers can find the optimal structural parameters of the hydrostatic bearing in more extensive scope with the aid of a computer. The extrusion effect of oil film on the dynamic response is very obvious, and it can be used even to determine whether a hydrostatic bearing can work normally. So, it demands that designers should take care of extrusion effect in the establishment of an optimization model.

Table 1

\begin{tabular}{c|c|c|c|c}
\hline $\begin{array}{c}\text { Mechanical } \\
\text { efficiency } \eta_{\mathrm{m}}(\%)\end{array}$ & $\begin{array}{c}\text { Volume efficiency } \\
\eta_{\mathrm{V}}(\%)\end{array}$ & $\begin{array}{c}\text { Total efficiency } \\
\eta(\%)\end{array}$ & $\begin{array}{c}\text { Stiffness of } \\
\text { Bearing } \mathrm{J}(\mathrm{N} / \mathrm{mm})\end{array}$ & $\begin{array}{c}\text { Beaving function } \\
\alpha\end{array}$ \\
\hline 99.919 & 98.898 & 98.818 & $1.366 \times 10^{6}$ & 0.88 \\
\hline
\end{tabular}

\section{REFERENCE}

1. P. J. Chapple, The effect of frictional loss and leakage on the performance of hydraulic motors, Fluid power, 8, 1988.

2. He Guangzhi, The analysis of dynamic characteristics in hydraulic pumps and motors, Hydraulic Technology in Vessel and Ship(P. R. China), 1979. 8.

3. S. U. Cunningham and D. Mcgillivray, Design and operation of hydrostatic bearings in hydrostatic motors, Proc Instn Mech Engrs, 1965. vol. 180.

4. Gu Qiangai, CAD for hydrostatic bearings, 7th International symposium, 1986. 9.

5. Chen Zhuoru, The theory, calculation and design of high torque low speed hydraulic motors, Mech Indr Prs (P. R. China), 1989. 6.

6. Xu Yaoming, The theory of oil film and the design of the friction pairs in hydraulic pumps and motors, Mech Indr Prs (P. R. China), 1987.3. 